\title{
Relaxant mechanism of Eulophia macrobulbon ethanolic extract and 1-(4'-hydroxybenzyl)-4,8-dimethoxyphenanthrene-2,7-diol on human corpus cavernosum
}

\author{
Chaweewan Jansakul ${ }^{1}$, Somreudee Yorsin ${ }^{2}$, Jomkarn Naphatthalung ${ }^{1}$, Kuldej \\ Tachanaparugse $^{3}$, Kanokwan Changwichit ${ }^{4}$, Krongkarn Chootip ${ }^{5}$ and \\ Kornkanok Ingkaninan ${ }^{4}$
}

\begin{abstract}
${ }^{1}$ Faculty of Traditional Thai Medicine, Prince of Songkla University, Songkhla 90110, Thailand; ${ }^{2}$ Faculty of Medicine, Princess of Naradhiwas University, Narathiwas, Thailand; ${ }^{3}$ Rajyindee Hospital, Hat-Yai 90110, Thailand; ${ }^{4}$ Bioscreening Unit, Department of Pharmaceutical Chemistry and Pharmacognosy, Faculty of Pharmaceutical Sciences and Center of Excellence for Innovation in Chemistry, Naresuan University, Phitsanulok 65000, Thailand; ${ }^{5}$ Department of Physiology, Faculty of Medical Science, Naresuan University, Phitsanulok 65000, Thailand
\end{abstract}

Corresponding author: Chaweewan Jansakul, $\mathrm{PhD}$, Faculty of Traditional Thai Medicine, Prince of Songkla University, Hat-Yai, Thailand 90110.

Submission date: Dec 28 ${ }^{\text {th }}$, 2018; Acceptance Date: May $28^{\text {th }}$, 2019. Publication Date: May $30^{\text {st }}, 2019$.

Citation: Jansakul C., Yorsin S., Naphatthalung J., Tachanaparugse K., Changwichit K., Chootip K., Ingkaninan K. Relaxant mechanism of Eulophia macrobulbon ethanolic extract and 1-(4'-hydroxybenzyl)-4,8-dimethoxyphenanthrene-2,7-diol on human corpus cavernosum. Functional Foods in Health and Disease 2019; 9(5): 328-340. DOI: https://doi.org/10.31989/ffhd.v9i5.591

\begin{abstract}
Background: Eulophia macrobulbon (E.C.Parish and Rchb.f.) Hook.F. has been shown to be a promising phosphodiesterase-5 (PDE5) inhibitor that relaxes rat isolated pulmonary artery.
\end{abstract}

Objective: To test this plant's possible application in human erectile dysfunction (ED) using an ethanolic extract of E. macrobulbon tubers (EM extract), and an isolated constituent, 1-(4'hydroxybenzyl)-4,8-dimethoxyphenanthrene-2,7-diol (HDP).

Methods: Dried tubers of E. macrobulbon (EM) were extracted with 95\% ethanol and the HDP was isolated by open column chromatography and high-performance liquid chromatography (HPLC) methods. The relaxant mechanism of the EM extract and the HDP was studied on isolated human cavernosal (HC) strips.

Results: EM extract relaxed $\mathrm{HC}$ strips, and this effect was not modified by $\mathrm{N}^{\mathrm{G}}$-nitro-L-arginine (L-NNA), ODQ, tetraethylammonium, nor glybenclamide. HDP relaxed HC strips to the same extent as that of sildenafil. EM extract and HDP potentiated relaxation of the HC strips to glyceryl trinitrate in a similar manner to that of sildenafil. EM extract and sildenafil, but not HDP, increased cGMP content of the HC strips in a concentration-dependent manner. In the 
thapsigargin-pretreated HC strips, nifedipine or EM extract, but not HDP, suppressed the contractile response of the HC strips to phenylephrine. When nifedipine and/or SKF 96365 were added, followed by EM extract or HDP, further suppression was found in the case of HDP but not with EM extract. $\mathrm{Ca}^{2+}$ free Krebs solution, suppressed the phenylephrine contraction on HC strips and further suppression was found when adding EM extract or HDP.

Conclusion: These results indicate that EM extract causes a relaxation of $\mathrm{HC}$ strips by serving as an inhibitor of PDE5, of voltage- and stored-operated $\mathrm{Ca}^{2+}$ channels, and of intracellular $\mathrm{Ca}^{2+}$ mobilization. Thus, EM extract might be a good choice for development as a functional food for erectile dysfunction in men. However, further studies are needed to identify other PDE5 and the $\mathrm{Ca}^{2+}$ channel inhibiting components of the extract.

Keywords: Eulophia macrobulbon; human cavernosum; phosphodiesterase-5 inhibitor; sildenafil; $\mathrm{Ca}^{2+}$ channel inhibitor

\section{Human Ethic Number: EC.57/B 06-004}

\section{BACKGROUND}

Erectile dysfunction (ED) or impotence is the persistent inability to attain and maintain an erection during intercourse [1]. ED is recognized throughout the world as a serious problem for men. Medications such as inhibitors of phosphodiesterase 5 (PDE5), agents that inhibit cGMP hydrolysis, are often sought to treat this condition since they could promote corpus cavernosum relaxation resulting in prolongation of penile erection [2-5].

Penile erection is a hemodynamic process involving relaxation of smooth muscle of the corpus cavernosum, which results to increase flow of blood into the trabecular space of the corpus cavernosa [6-7]. Smooth muscle relaxation is mediated by nitric oxide (NO) released from endothelial cell lining blood vessels, the lacunar space of the corpora cavernosa, and the parasympathetic non-adrenergic, non-cholinergic neuron in the penis [8-11]. NO activates soluble guanylate cyclase that increased conversion of guanosine triphosphate (GTP) to cyclic guanosine monophosphate (cGMP) [8] provides the signal which leads to relaxation of smooth muscle of the corpus cavernosum and penile arterioles. PDE5 is the predominant cyclic guanosine monophosphate (cGMP) degrading enzyme found in platelets, penile corpus cavernosum, smooth muscle cells, and all vascular smooth muscle cells particularly in the pulmonary vessels [12-13]. Inhibition of PDE5 increasesc GMP, thus enhancing the nitric oxide (NO)/ cGMP signaling pathway leading to vascular smooth muscle relaxation of penile corpus cavernosum [3, 14-15]. Although various PDE5 inhibitors e.g. sildenafil, vardenafil and tadalafil have been clinically used for erectile dysfunction, these standard synthetic inhibitors may cause nausea, headache, and cutaneous flushing [16]. Thus, interest turns to natural substances with perceived lower side effects [17].

Our previous study showed that the tubers of Eulophia macrobulbon (E.C. Parish and Rchb.f.) Hook. f., a plant in the Orchidaceae family, inhibited PDE-5. This plant can be found throughout Asia. The major PDE-5 inhibitor in the plant has been isolated and identified as 1(4'-hydroxybenzyl)-4,8-dimethoxyphenanthrene-2,7-diol (HDP) (Figure 1) [18]. Both an ethanolic extract of E. Macrobulbon tuber and HDP relax pulmonary [19] and mesenteric arteries [20] relieve pulmonary hypertension in rats [19]. Since the same signaling mechanisms operate in penile erection, EM extract may find an application in ED. Here, we use standard pharmacological techniques to investigate the potential role of EM extract and HDP in the 
cellular pathway using the relevant tissue, human corpus cavernosum, as a prelude to their possible development for clinical application to ED.

\section{Materials}

The following drugs were used, acetylcholine chloride, nifedipine, $\mathrm{N}^{\mathrm{G}}$-nitro-L-arginine (LNNA), phenylephrine hydrochloride, tetraethylammonium (TEA) obtained from Sigma, St. Louis, MO, USA.1H-[1,2,4]oxadiazolo[4,3-a]quinoxalin-1-one (ODQ) was obtained from Trocis, UK. Sildenafil citrate (Viagra) was from Pfizer. Glyceryl trinitrate (GTN) was from Mycomed, Denmark. L-NNA, GTN and sildenafil were dissolved in distilled water, nifedipine was dissolved in DMSO (20\%) and the other chemicals were dissolved in a solution (1 liter) containing $\mathrm{NaCl}(9 \mathrm{~g}), \mathrm{NaH}_{2} \mathrm{PO}_{4}(0.19 \mathrm{~g})$, and ascorbic acid (0.03 g). Methanol and dichloromethane were purchased from Carlo Erba, France. All solvents were analytical grade purity. A standard HDP was isolated and purified from E. Macrobulbon [18].

\section{MEDTHODS}

\section{Preparation of plant extractand isolation of $\mathrm{HDP}$}

Fresh tubers of EM were collected from Prachinburi province, Thailand. The voucher specimen (No.002716) was identified by Associate Professor Dr. Anupan Kongbungkerd, Department of Biology, Naresuan University, Thailand and therein lodged. EM extract was prepared from 2 $\mathrm{kg}$ of dried, powdered tubers, macerated with 95\% ethanol (14 L, $3 \mathrm{~d}$ ) twice and filtered and evaporated by vacuum to yield $15.8 \%(\mathrm{w} / \mathrm{w})$ of extract. The extract contained $0.52 \%(\mathrm{w} / \mathrm{w})$ of HDP analyzed by HPLC. The HPLC separation was performed on a Gemini-NX C18 column ( $150 \times 4.0 \mathrm{~mm}$ i.d., $5 \mu \mathrm{m}$ particle size) with gradient elution of a mobile phase comprising 0.05 $\mathrm{M}$ sodium acetate $(\mathrm{pH} 3.7)$ and acetonitrile. The injection volume was $20 \mu \mathrm{l}$. The flow rate was adjusted to $1 \mathrm{ml} / \mathrm{min}$ and detection was performed at $265 \mathrm{~nm}$. The TLC fingerprint of the extract was also recorded [21].

HDP was isolated from EM extract as described by Temkitthawon et al. [18] and Changwichit et al. [21]. The purity of the compound was more than $95 \%$ analyzed by NMR and HPLCas described previously [18] and as shown in Figure 1B. The EM extract and HDP were stored at $-20^{\circ} \mathrm{C}$ until used.

The chemical profile of EM extract and HDP were established using high performance liquid chromatography (HPLC). The extract was analyzed by using HP 1100 system (Agilent) comprising of a photodiode array detector and C18 column (Waters) with gradient flow of methanol:water $(5: 95 \rightarrow 100: 0)$ containing $\mathrm{C}_{2} \mathrm{HF}_{3} \mathrm{O}_{2} 0.05 \%$ at $1 \mathrm{ml} / \mathrm{min}$ flow and detected by UV- DAD (200-600 nm).

\section{Pharmacological studies}

\section{Preparation of human cavernosal strips}

\section{A) Patients}

Cavernosal tissue was obtained from20potent healthy men (age 22-30 years) who had elected for penile amputations for gender changeand whohad been discontinued treatment with antiandrogens and estrogens two months before surgery. All protocols were approved by the Human Ethics Committee Faculty of Traditional Thai Medicine Review Board, Prince of Songkla University (EC. 57/B 06-004). Research carried out on human was incompliance with the Helsinki Declaration. All participants provided informed written consent. 


\section{B) Tissue preparation}

Cavernosal strips were prepared using a method modified from Mirone et al. [22]. The amputated penis was carefully placed in cold Krebs-Heinseleit solution equilibrated with carbogen $\left(\mathrm{O}_{2} / \mathrm{CO}_{2}\right)$ and washed twice with this solution. The penes were opened along the median section, and longitudinal strips of about $2 \times 7 \mathrm{~mm}(\mathrm{WxL})$ were dissected ( 8 strips per patient). These cavernosal strips were mounted in $20 \mathrm{ml}$ tissue baths maintained at $37^{\circ} \mathrm{C}$ containing Krebs-Heinseleit solution (mM: $\mathrm{NaCl} 118.3, \mathrm{KCl} 4.7, \mathrm{CaCl}_{2}$ 1.9, $\mathrm{MgSO}_{4} 0.45$, $\mathrm{KH}_{2} \mathrm{PO}_{4} 1.18$, glucose 11.7, $\mathrm{Na}_{2}$ EDTA $0.024, \mathrm{NaHCO}_{3}$ 25.0, ascorbic acid 0.09). The HC strip was connected to a force-transducer (FT03C) and bridge amplifiers (Grass Instruments, Quincy, Mass, USA), basal tension adjusted to $1.0 \mathrm{~g}$, maintained at $37{ }^{\circ} \mathrm{C}$ and continuously bubbled with $\mathrm{O}_{2} / \mathrm{CO}_{2}$ mixture (95\%: 5\%). The strips were equilibrated for $60 \mathrm{~min}$ in KrebsHeinseleit $(\mathrm{K}-\mathrm{H})$ solution refreshed every $15 \mathrm{~min}$. After equilibration, the presence of functional endothelium of the $\mathrm{HC}$ strip was assessed through the following methods: $1 \mu \mathrm{M}$ phenylephrine was added to produce a sustained contracture (after $10 \mathrm{~min}$ ) on which a relaxation was superimposed by application of $10 \mu \mathrm{M}$ Ach. HC strips having a relaxation $>80 \%$ were deemed usable. Phenylephrine/ Ach were removed by several washouts with K-H solution until contraction returned to baseline and equilibrated for $45 \mathrm{~min}$ before the experiment began. Each experiment proceeded by adding phenylephrine. The drugs were added cumulatively, and the effect of drug-induced relaxation was measured as the decline from the maximal steady tension produced by phenylephrine $(0.3 \mu \mathrm{M}$ for the ones with L-NNA and $3 \mu \mathrm{M}$ for the ones without L-NNA).

\section{Relaxant activity of EM extract, sildenafil and HDP}

Phenylephrine $(3 \mu \mathrm{M})$ was added to $\mathrm{HC}$ strips until the contraction reached a plateau (10 min), and then either EM extract (0.1-3mg/ml), HDP (0.1-3 mM), or sildenafil (0.1-3 mM) were added in accumulating concentrations. The EM extract, sildenafil and HDP induced relaxation $(\%)$ was calculated as the percentage of the maximal contraction at the plateau state established byphenylephrine.

\section{Role of nitric oxide, guanylate cyclase and $\mathrm{K}^{+}$channels}

To test the role of these pathways, HC strips were precontracted with phenylephrine $(3 \mu \mathrm{M}$ or $0.3 \mu \mathrm{M}$ when L-NNA used) and EM extract $(0.1-3 \mathrm{mg} / \mathrm{ml})$ added accumulatively. After several washings followed by re-equilibration of the HC strips for $1 \mathrm{~h}$, the HC strips were incubated with $1 \mathrm{H}-[1,2,4]$ oxadiazolo [4,3-a] quinoxaline-1-one (ODQ, $10 \mu \mathrm{M}$, a guanlylate cyclase inhibitor [23]), glybenclamide $\left(10 \mu \mathrm{M}\right.$, a $\mathrm{K}_{\mathrm{ATP}}$-blocker [24]) or tetraethylammonium (TEA,1 $\mathrm{mM}$, a $\mathrm{K}_{\mathrm{Ca}}$-channel blocker [25]) and/or $\mathrm{N}^{\mathrm{G}}$-nitro-L-arginine (L-NNA, $3 \mathrm{mM}$, a nitric oxide synthase inhibitor [26]) for 20min. Then, the impact of EM extract on $C-R$ relationship was determined in the presence of the respective drug beginning with the appropriate concentration of phenylephrine.Percentage relaxation of each drug was determined as described above.

\section{Phosphodiesterase inhibition}

Nitric oxide is a direct activator of guanylate cyclase which converts GTP to cGMP which is constitutively hydrolyzed by PDE5. 
To assess the role of EM extract or HDP as a PDE5 inhibitor in comparison to the sildenafil (a PDE5 inhibitor [27]), a cumulative relaxation $C-R$ curve to glyceryl trinitrate, a nitric oxide donor, on the HC strip precontracted with phenylephrine $(3 \mu \mathrm{M})$ was performed. Following several washings, the HC strip was incubated with sildenafil $(3 \mathrm{mM})$, EM extract $(3 \mathrm{mg} / \mathrm{ml})$ or HDP $(3 \mathrm{mM})$ for $20 \mathrm{~min}$ and the relaxation $C-R$ relationship to glyceryl trinitrate on the phenylephrine-precontracted HC strip was obtained in the presence of the incubating drugs. Percentage relaxation of each drug was determined as described above.

\section{cGMP measurement by ELISA}

HC strips were incubated in tissue baths containing L-NNA (3 $\mathrm{mM})$ alone (control) or with (1) $1 \mathrm{mM}$ sildenafil, (2) $3 \mathrm{mM}$ sildenafil, (3) $1 \mathrm{mg} / \mathrm{ml} \mathrm{EM}$, (4) $3 \mathrm{mg} / \mathrm{ml} \mathrm{EM,} \mathrm{(5)} 1 \mathrm{mM}$ HDP or (6) $3 \mathrm{mM} \mathrm{HDP}$, for $30 \mathrm{~min}$. The HC strip of each incubating medium was collected and kept in $-70^{\circ} \mathrm{C}$ until used. Each frozen $\mathrm{HC}$ strip was chopped on ice and homogenized in $0.1 \mathrm{M} \mathrm{HCl}$ $(0.4 \mathrm{~g}$ of tissue in $1 \mathrm{ml}$ of $0.1 \mathrm{M} \mathrm{HCl})$. The lysates were centrifuged $(14,000 \mathrm{rpm}$ for $10 \mathrm{~min})$ and supernatants were collected for cyclic nucleotide competitive ELISA (Enzo, USA), and was performed according to the manufacture's guidelines. Cyclic nucleotide content was normalized to sample total protein content of each sample (by Bradford assay).

\section{Role of voltage-or stored-operated $\mathrm{Ca}^{2+}$ channels}

HC strips were treated with L-NNA for 60 min then incubated with thapsigargin $(1 \mu \mathrm{M})$, a SERCA pump inhibitor, for 40min to deplete the sarcoplasmic $\mathrm{Ca}^{2+}$ intracellular store which, in turn, opens of the plasma membrane store-operated $\mathrm{Ca}^{2+}$ channels. Then, the contractile responses to phenylephrine $(3 \mu \mathrm{M})$ were determined before and after adding of the EM $(3 \mathrm{mg} / \mathrm{ml}), \mathrm{HDP}(3 \mathrm{mM})$ or nifedipine $\left(1 \mathrm{mM}\right.$, a voltage- $\mathrm{Ca}^{2+}$ channel inhibitor) alone or in combination of EM or HDP with nifedipine and/or SKF 96365 (3mM, a store-operated $\mathrm{Ca}^{2+}$ channel inhibitor). Percent contraction to phenylephrine in the presence of each drug or in combinationwas calculated against the maximal plateau contraction established by the phenylephrine alone.

\section{Inhibition of intracellular $\mathrm{Ca}^{2+}$ mobilization}

To determine whether EM or HDP plays a role as an inhibitor of an intracellular $\mathrm{Ca}^{2+}$ mobilization, contractile responses to phenylephrine $(3 \mu \mathrm{M})$ on the $\mathrm{HC}$ strips were performed in the $\mathrm{Ca}^{2+}$ free Krebs solution before and after incubating with EM ( $\left.3 \mathrm{mg} / \mathrm{ml}\right)$ or HDP (3mM) in the presence of L-NNA.Percent contraction to phenylephrine in the $\mathrm{Ca}^{2+}$ free Krebs solution, EM extract or HDP was calculated against the maximal plateau contraction established by phenylephrine alone in normal $\mathrm{Ca}^{2+} \mathrm{Krebs}$ solution.

\section{Statistical analysis}

Results are expressed as a mean \pm standard error of the mean (SEM) where $n$ indicates number of HC strips obtained from different patients. Statistical comparison was performed using the statistical differences between 2 measurements as determined by the two-tailed unpaired or paired Student's t-testand among the group was determined by one-way ANOVA. Post-hoc 
analysis was performed with Tukey's range testusing GraphPad Prism 5. A $p$ value $\leq 0.05$ was considered to indicate a significant difference between values.

\section{RESULTS}

\section{Biochemical analysis of the EM extract}

The HPLC chromatogram of EM extract was shown in Figure 1. There are 4 HPLC major peaks detected at the wavelength of $254 \mathrm{~nm}$ at the retention time (min) of 14.58, 18.50, 20.35, and 20.91 for the HPLC peak 1 to 4, respectively. On UV spectral analysis, HPLC-peak 4 is equivalent to the HDP which has retention time at 20.97 with a similar of peaks UV spectrums.

\section{A EM extract, $10 \mathrm{mg} / \mathrm{ml}$}

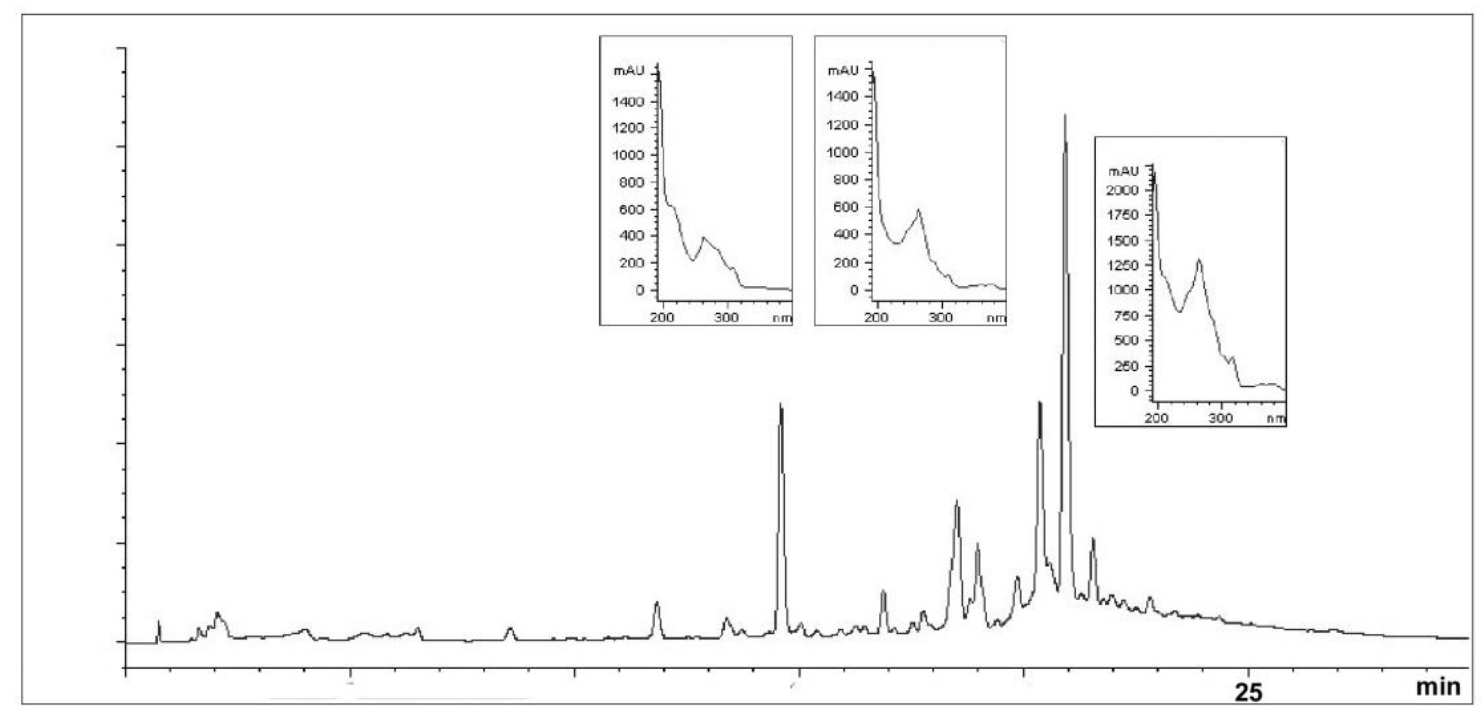

\section{B HDP, $0.1 \mathrm{mg} / \mathrm{ml}$}

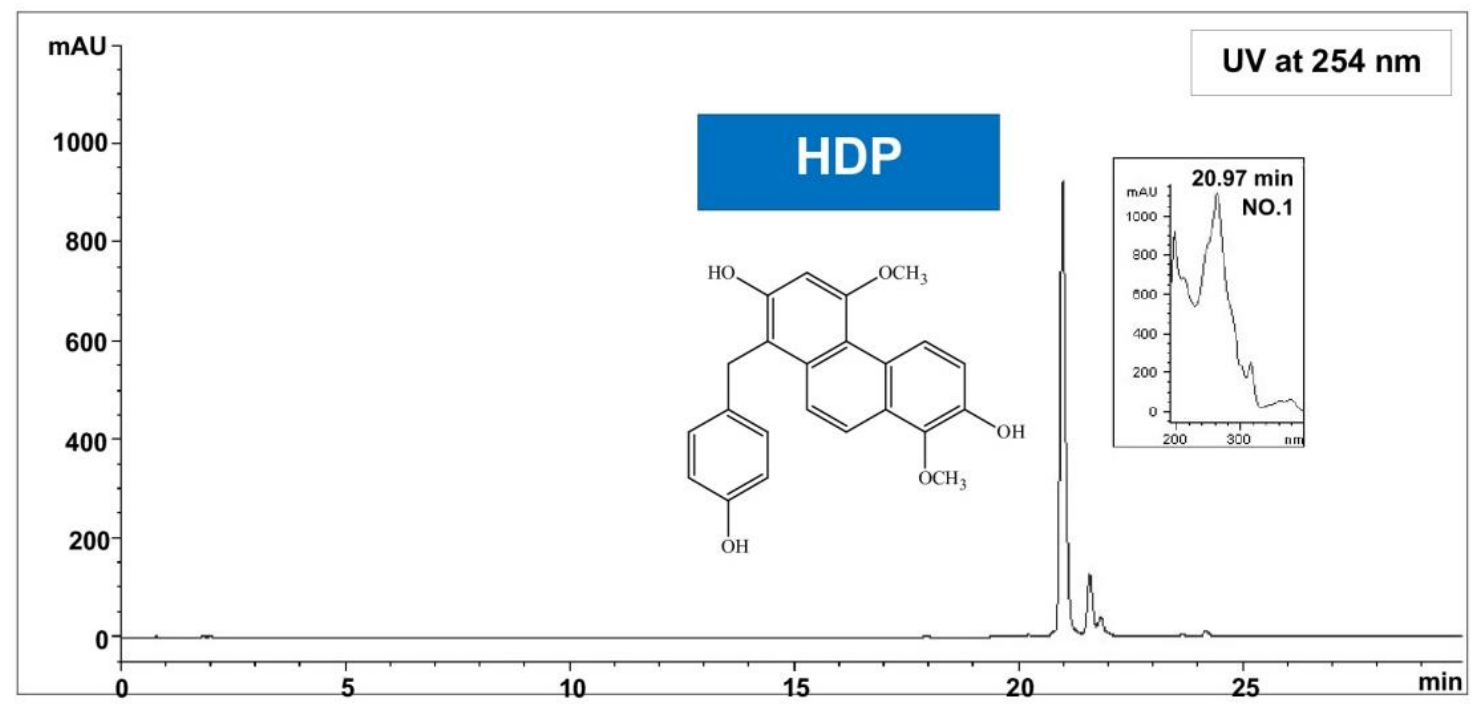

Figure 1. HPLC chromatogram of EM extract (A) and 1-(4'-hydroxybenzyl)-4,8dimethoxyphenanthrene-2,7-diol) HDP (B). The column eluent for each of the 4 EM extract peaks was scanned at the wavelength of $254 \mathrm{~nm}$. Retention time in minute of each peak is shown as a miniature of each peak of its UV spectra. 


\section{Relaxations induced by EM extract, sildenafil and HDP}

EM extract (0.1-3 mg/ml), sildenafil (0.1-3 mM), and HDP (0.1-3 mM), each reproducibly and reversibly relaxed $\mathrm{HC}$ strips precontracted by phenylephrine in a concentration-dependent manner (Figure2).
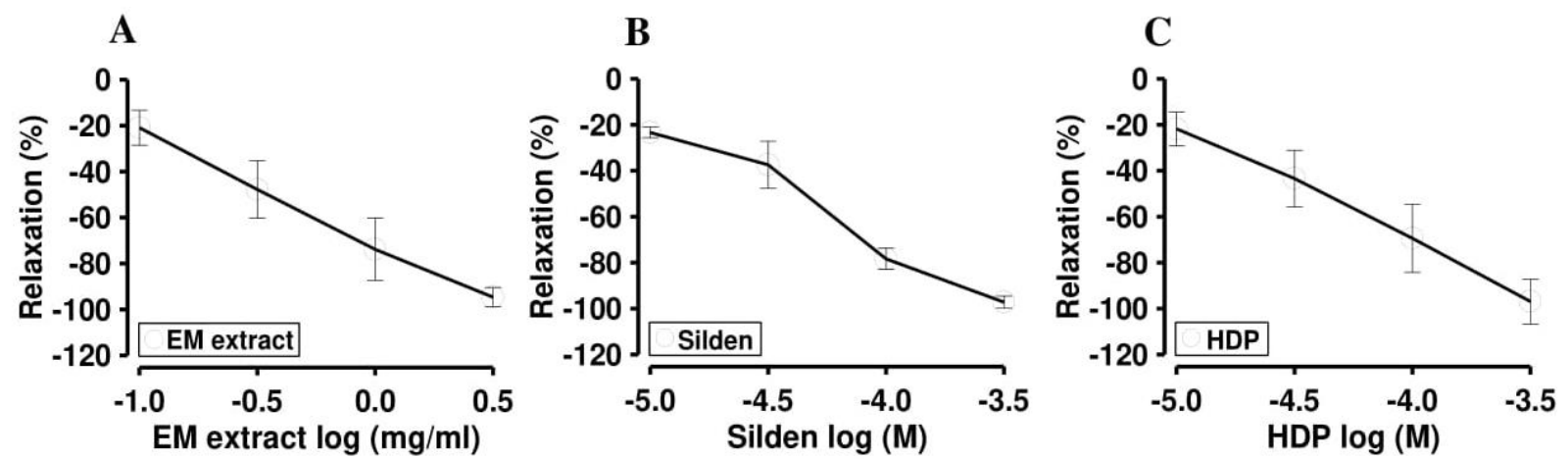

Figure 2. Relaxation of $\mathrm{HC}$ strips precontracted with phenylephrine to EM extract (A), sildenafil (B) or $\operatorname{HDP}(C)$. Each point represented mean \pm SEM, $n=6$.

\section{Role of nitric oxide, guanylate cyclase and $\mathrm{K}^{+}$channels}

The blockers of NOS (L-NNA), guanylate cyclase (ODQ), and the BK- (TEA) and $\mathrm{K}_{\text {ATP }}$ channels (glybenclamide) that predominantly mediate relaxation of the HC muscle [28], did not modulate the EM extract- induced relaxation (Figure3).
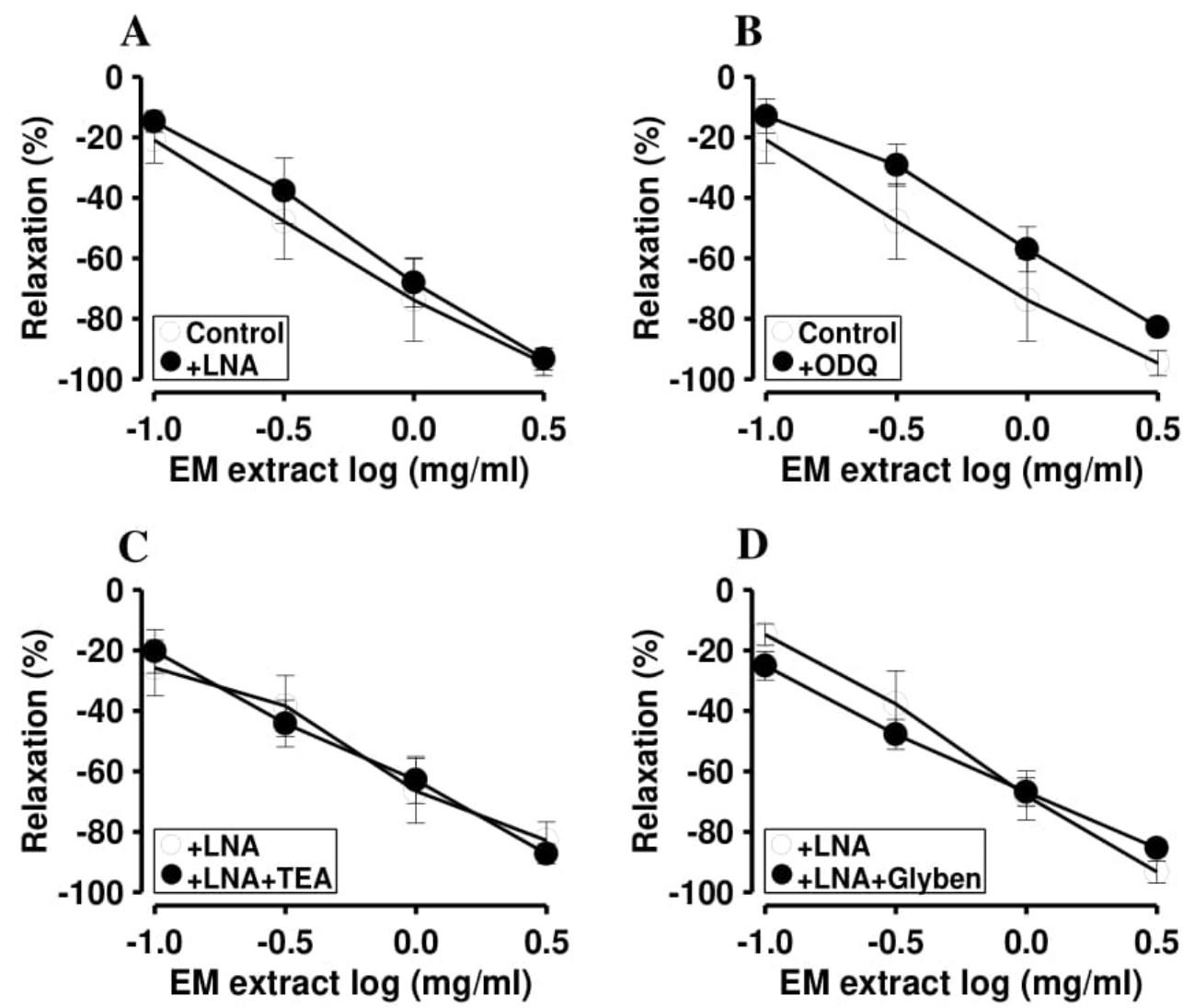

Figure3. Relaxations of HC strip precontracted with phenylephrine. The roles of nitric oxide synthase, guanylate cyclase, and $\mathrm{K}^{+}$channels were tested using N-nitro-L-arginine (L-NNA), ODQ, and TEA or glybenclamide. Each point represented mean \pm SEM, $n=6$. 


\section{Phosphodiesterase inhibition}

Glyceryltrinitrate, a nitric oxide donor, caused a relaxation of precontracted HC strips in a concentration dependent manner. The relaxation by the glyceryl trinitrate was potentiated by incubating the HC strip with sildenafil, the EM extract or the HDP (Figure 4A-C).

A Sildenafil (3 mM)

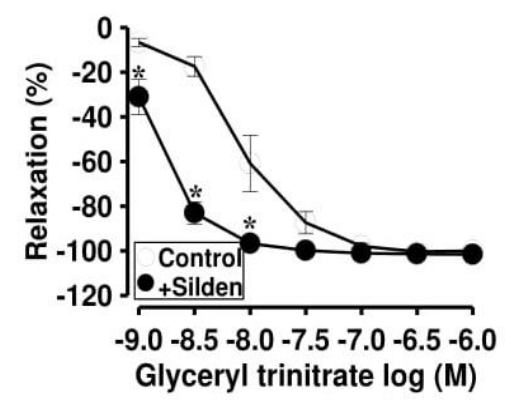

B EM extract $(3 \mathrm{mg} / \mathrm{ml})$

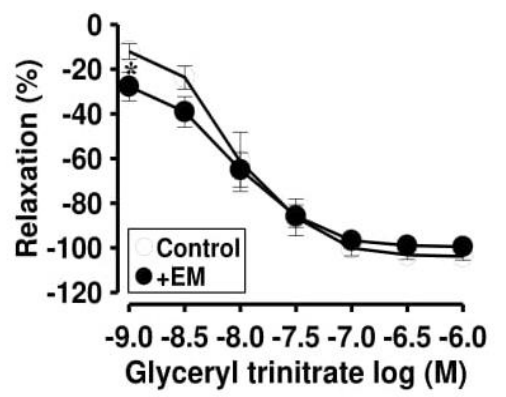

C HDP (3 mM)

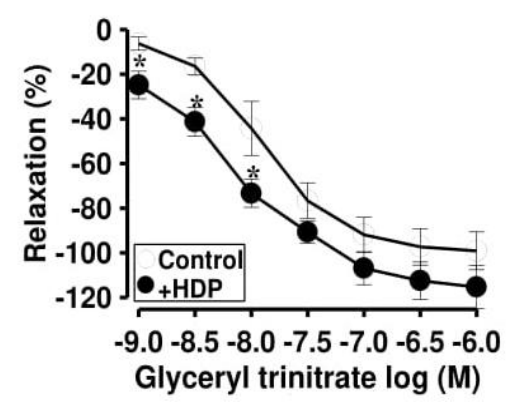

Figure 4. Effects of sildenafil, EM extract or HDP on relaxation of HC strip precontracted with phenylephrine to glyceryltrinitrate. Each point represented mean \pm SEM, $n=6$. " significantly lower than the control group, $p<0.05$.

\section{cGMP levels}

Sildenafil and EM extract increased cGMP contents of HC strips in a concentration-dependent manner, whereas HDP only had a modest effect (Figure 5).

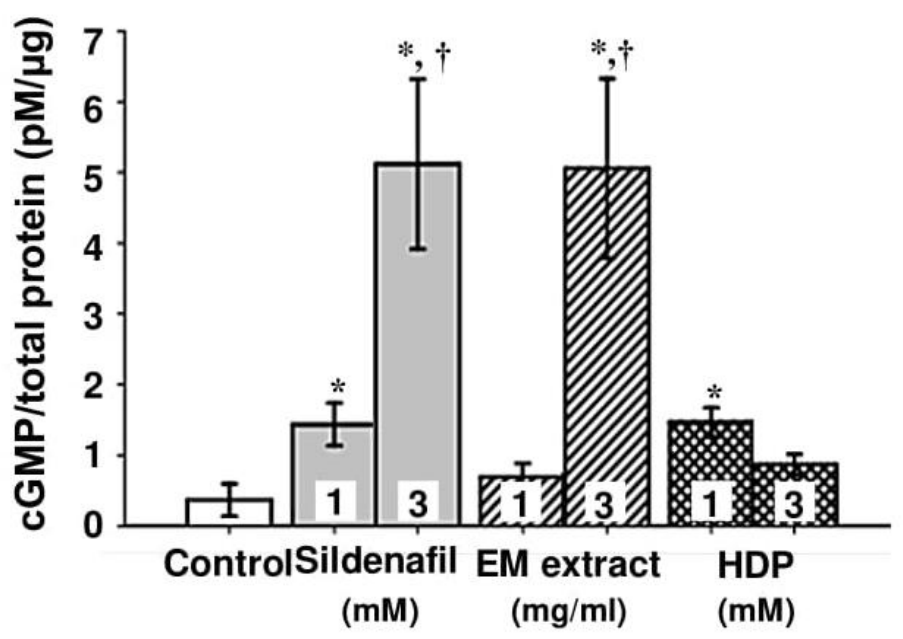

Figure 5. cGMP contents of human cavernosal muscle strips after $30 \mathrm{~min}$ of preincubation with L-NNA (control) alone, or L-NNA with sildenafil (1 or $3 \mathrm{mM}$ ), EM extract ( 1 or $3 \mathrm{mg} / \mathrm{ml}$ ) or HDP $(1$ or $3 \mathrm{mM})$. Each bar graph represented mean \pm SEM, $\mathrm{n}=6$. ${ }^{*}$ significantly higher than the control group, ${ }^{\dagger}$ significantly higher than their own group with lower concentration, $p<0.05$.

\section{Inhibition of voltage-or stored-operated calcium channels}

If EM extract or HDP plays a role as a voltage-gated $\mathrm{Ca}^{2+}$ channel inhibitor and/or a storeoperated $\mathrm{Ca}^{2+}$ channel inhibitor, the contractile response of the $\mathrm{HC}$ strip to phenylephrine in the presence of EM extract or HDP would not be modified by the addition of nifedipine and/or SKF-96365 under conditions where store-operated $\mathrm{Ca}^{2+}$ channels are also activated. In order to stimulate opening of the store-operated $\mathrm{Ca}^{2+}$ channels, the $\mathrm{HC}$ strips were incubated with thapsigargin $(1 \mu \mathrm{M})$, a SERCApump inhibitor, to deplete the intracellular $\mathrm{Ca}^{2+}$ store in the sarcoplasmic reticulum and this inturn stimulated the opening of the plasma membrane storeoperated $\mathrm{Ca}^{2+}$ channel [29-32]. 
In the presence of L-NNA and thapsigargin, either nifedipine or EM extract, but not HDP, each suppressed the contractile responses of the HC strips to phenylephrine. When EM extract was added together with nifedipine, or nifedipine with SKF96365, no further suppression of the phenylephrine contraction obtained (Figure 6A). On the other hand, when HDP was added together with nifedipine or nifedipine with SKF96365, a further suppression was found (Figure 6B).

A

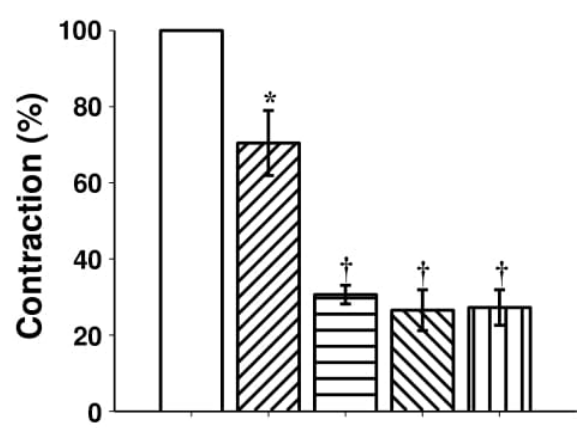

EM (3 $\mathrm{mg} / \mathrm{ml})$

Nifedipine (3 mM)

$\operatorname{SKF}(1 \mathrm{mM})$

TG+L-NNA
B

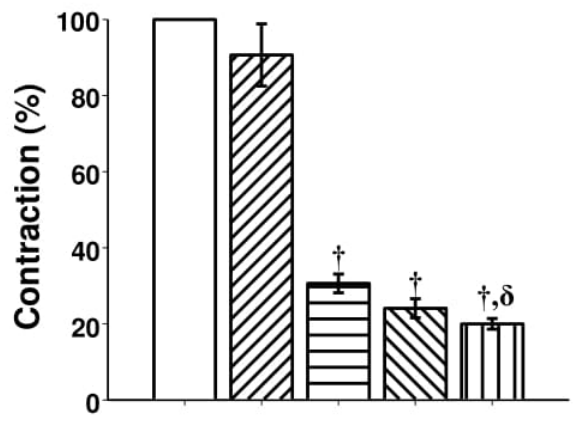

HDP (3 mM)

Nifedipine (3 mM)

SKF (1 mM)

TG+L-NNA

Figure 6. Effects of EM extract, HDP, nifedipine and/or SKF 96365 on contractile responses of the phenylephrine on the HC strips. Each point represented mean \pm SEM, $n=6$. *significantly lower than the one with L-NNA+TG) control group, 'significantly lower than the one with L-NNA + TG and the one with L-NNA + TG and with EM extract or with HDP and ${ }^{\delta}$ significantly lower than the one with L-NNA + TG + nifedipine, $p<0.05$.

\section{Inhibition of intracellular $\mathrm{Ca}^{2+}$ mobilization}

In the $\mathrm{Ca}^{2+}$ free Krebs solution, the contractile responses to phenylephrine on the HC strip in the presence of L-NNA were depressed. Further suppression was found when EM extract or HDP was also added into the incubation medium (Figure 7).

A

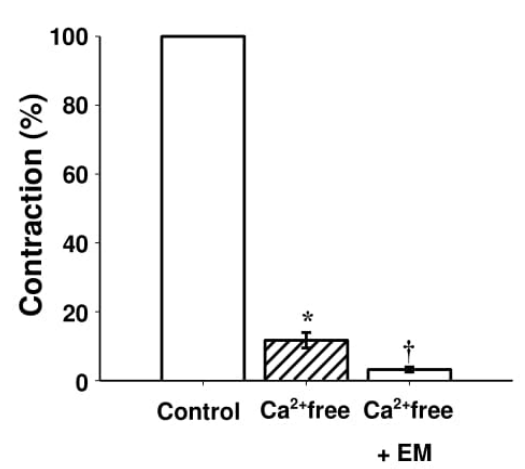

B

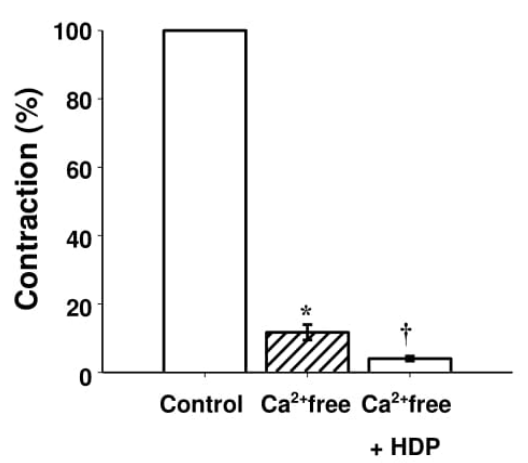

Figure 7. Contractile responsiveness of the $\mathrm{HC}$ strips to $3 \mu \mathrm{Mphenylephrinein} \mathrm{normal} \mathrm{Krebs}$ solution with $\mathrm{Ca}^{2+}$ (control) or in $\mathrm{Ca}^{2+}$ free Krebs solution alone, in the presence of EM extract or HDP. L-NNA (30 $\mathrm{mM}$ ) was present throughout. Each point represented mean $\pm \mathrm{SEM}, \mathrm{n}=6$. *significantly lower than control and ${ }^{\dagger}$ significantly lower than the other groups, $p<0.05$. 


\section{DISCUSSION}

EM extract or HDP clearly relaxed isolated HC strips. Further experiments explored the underlying mechanisms for the relaxation activity on nitric oxide synthase stimulator, a guanylate cyclase stimulator, opening of $\mathrm{K}^{+}$channels, a PDE-5 inhibitor, inhibiting the voltageor stored-operated calcium channels, or inhibiting the intracellular $\mathrm{Ca}^{2+}$ mobilization.

The finding that L-NNA, a nitric oxide synthase inhibitor; or ODQ, a guanylate cyclase inhibitor, did not inhibit the relaxant activity of the EM extract, suggests that the EM extract did not stimulate the nitric oxide synthase nor the soluble guanylate cyclase pathway. However, the main nitric oxide source in cavernosum is not only at the sinus endothelium, but also at the nitrinergic nerve terminals which requires an electrical stimulation at the intact nerve supply to release nitric oxide. Thus, further experiments using electrical stimulation to evoke NO may reveal a more conclusive role for nitric oxide.

It is unlikely that the EM extract activated the $\mathrm{K}^{+}$channel either the $\mathrm{Ca}^{2+}$ sensitive $\mathrm{K}^{+}$ channel $\left(\mathrm{K}_{\mathrm{Ca}}\right)$ [25], or the ATP-sensitive $\mathrm{K}^{+}$channel ( $\left.\mathrm{K}_{\mathrm{ATP}}\right)$ [24], as it was found that neither TEA nor glybenclamide inhibited the relaxation C-R curve of the EM extract.

The finding that EM extract and HDP potentiated the relaxant activity of the glyceryl trinitrate on the HC strip similar to what would be produced by sildenafil, a known PDE5 inhibitor [33] suggests that EM extract and HDP might act as a PDE5 inhibitor. To confirm this, we conducted another experiment by measuring cGMP concentration in HC strips by ELISA method, where the HC strips had been incubated with EM extract, HDP or sildenafil in the presence of L-NNA in order to prevent cGMP disturbance produced by the nitric oxide. The results showed that EM extract increased cGMP content in the HC strip in a concentration dependent manner, which was similar to that of the sildenafil. However, HDP caused only a slight increase in HC strip cGMP concentration independent of the HDP concentrations. These results indicated that HDP might have only mild PDE5 inhibitor activity. Thus, EM extract might contain other substance(s) that possess a PDE5 activity besides HDP further study is needed to investigate this.

EM extract and HDP might cause relaxation of the HC strip via a $\mathrm{Ca}^{2+}$ channel pathway. In order to identify such activity, the L-NNA treated-HC strips were pre-incubated with thapsigargin, a SERCA pump inhibitor to deplete the stored $\mathrm{Ca}^{2+}$, in the sarcoplasmic reticulum, which would allow opening of the membrane store-operated $\mathrm{Ca}^{2+}$ channels [29-32]. In the present study, we expected that if EM extract or HDP acted as a voltage-gated and/or stored-operated $\mathrm{Ca}^{2+}$-channel inhibitor. Thus, the phenylephrine-induced contraction would not be further suppressed in the presence of EM extract or HDP together with nifedipine (a voltage-gated $\mathrm{Ca}^{2+}$-channel inhibitor) and/or SKF 96365 (a store-operated $\mathrm{Ca}^{2+}$ channel inhibitor). It was found that nifedipine, a voltagegated $\mathrm{Ca}^{2+}$ channel blocker, suppressed the HC strip contraction to phenylephrine. When EM extract was added together with nifedipine or together with nifedipine plus SKF 96365, no further suppression was found, indicating that the EM extract might act in part as inhibitors of the voltage gated and stored-operated $\mathrm{Ca}^{2+}$ channels. In case of the HDP, further suppression of the phenylephrine-induced HC strip contraction was observed in the presence of nifedipine, as well as in the presence of nifedipine plus SKF 96365, indicating that HDP might not play a role as a voltage-gated or store-operated $\mathrm{Ca}^{2+}$-channels inhibitors.

In vascular smooth muscle, the $\alpha$-adrenoceptor-induced contraction in $\mathrm{Ca}^{2+}$-free medium is initiated by $\mathrm{Ca}^{2+}$ release from the intracellular $\left(\mathrm{IP}_{3}\right)$ store in the sarcoplasmicreticulum[3435]. In the present study, we investigated the effect of EM extract and HDP onthe HC strip in $\mathrm{Ca}^{2+}$-free medium and found that both substances caused further suppression of the 
phenylephrine contractile response on the HC strips. This suggests that EM extract and HDP might inhibit intracellular $\mathrm{Ca}^{2+}$ mobility.

\section{CONCLUSIONS}

This study used human cavernosal muscle strips, thus providing a reliable basis for preclinical data translation into clinical applications. The EM extract induces relaxant activity on HC strips by acting as a PDE5 inhibitor, which promotes NO/cGMP vascular smooth muscle relaxation signaling pathway and partly inhibiting voltage-gated and a store-operated $\mathrm{Ca}^{2+}$ channels. HDP is also a PDE5 inhibitor, and both EM extract and HDP inhibit intracellular mobilization. The study supports the possibility that EM extract would be a good choice as a functional food to limit the development of erectile dysfunction in men. However, further study is still required to identify other PDE5 and the $\mathrm{Ca}^{2+}$ channel inhibiting components of the extract.

List of Abbreviations: erectile dysfunction (ED), phosphodiesterase-5 (PDE-5),1-(4'hydroxybenzyl)-4,8-dimethoxyphenanthrene-2,7-diol (HDP), Eulophia macrobulbon ethanolic extract (EM extract), acetylcholine (Ach), N-nitro-L-arginine (L-NNA), sarco/endoplasmic reticulum $\mathrm{Ca}^{2+}$-ATPase (SERCA), High performance liquid chromatography (HPLC), Human cavernosal (HC)

Competing interests: The study was supported by the Agriculture Research Development Agency (Public Organization), the Center of Excellence for Innovation in Chemistry (PERCHCIC), Office of the Higher Education Commission (Ministry of Education) and the Thailand Research Fund (the grants no. IRN61W0005), Thailand.The authors declare no conflict of interest. The funding and the authors have no conflict of interest.

Authors' contributions: CJ designed and conducted the research. SY, JN, KC and KI conducted the research and performed statistical analysis. KT provided human corpus cavernosum obtained from patients who had undergone sex change. $\mathrm{CJ}, \mathrm{KI}$ and $\mathrm{KC}$ wrote the manuscript. All authors read and approved the final version of the manuscript.

Acknowledgments and Funding: This research was supported by the Agriculture Research Development Agency (Public Organization), the Center of Excellence for Innovation in Chemistry (PERCH-CIC), Office of the Higher Education Commission (Ministry of Education) and the Thailand Research Fund (the grants no. IRN61W0005), Thailand. We thank Prof. Michael J. Mulvany, Aarhus University, Denmark, for his valuable comments and editing the manuscript.

\section{REFERENCES}

1. Hatzimouratidis K, Amar E, Eardley I, Giuliano F, Hatzichristou D, Montorsi F, Vardi Y, et al.: Guidelines on male sexual dysfunction: erectile dysfunction and premature ejaculation. Eur Urol. 2010; 57:804-814.

2. Cai Z, Zhang J, Li H: Two birds with one stone: regular use of PDE5 inhibitors for treating male patients with erectile dysfunction and cardiovascular diseases. Cardiovasc drugs ther. 2019; 33:119-128.

3. Corbin JD, Francis SH, Webb DJ: Phosphodiesterase type 5 as a pharmacologic target in erectile dysfunction. Urology. 2002; 60:4-11. 
4. Ferguson III JE, Carson III CC: Phosphodiesterase type 5 inhibitors as a treatment for erectile dysfunction: Current information and new horizons. Arab J Urol. 2013; 11:222-229.

5. Wylie K, Kenney G: Sexual dysfunction and the ageing male. Maturitas. 2010; 65:2327.

6. Andersson KE, Wagner G: Physiology of penile erection. Physiol Rev. 1995; 75:191236.

7. Lue TF, Takamura T, Schmidt RA, Palubinskas AJ, Tanagho EA: Hemodynamics of erection in the monkey. J Urol. 1983; 130:1237-1241.

8. Burnett AL: Role of nitric oxide in the physiology of erection. Biol Reprod. 1995; 52:485-489.

9. Burnett AL, Lowenstein CJ, Bredt DS, Chang TS, Snyder SH: Nitric oxide: a physiologic mediator of penile erection. Science. 1992; 257:401-403.

10. Rajfer J, Aronson WJ, Bush PA, Dorey FJ, Ignarro LJ: Nitric oxide as a mediator of relaxation of the corpus cavernosum in response to nonadrenergic, noncholinergic neurotransmission. N Engl J Med. 1992; 326:90-94.

11. Trigo-Rocha F, Aronson WJ, Hohenfellner M, Ignarro LJ, Rajfer J, Lue TF: Nitric oxide and cGMP: mediators of pelvic nerve-stimulated erection in dogs. Am J Physiol. 1993; 264:H419-422.

12. Bender AT, Beavo JA: Cyclic nucleotide phosphodiesterases: molecular regulation to clinical use. Pharmacol Rev. 2006; 58:488.

13. Lin CS: Tissue expression, distribution, and regulation of PDE5. Int J Impot Res. 2004; 16:S8-S10.

14. Beavo JA, Francis SH, Houslay MD: Cyclic nucleotide phosphodiesterases in health and disease. In: Francis SH, Zoraghi R, Kotera J, Ke H, Bessay EP, Blount MA, Corbin JD eds. Phosphodiesterase-5: molecular characteristics relating to structure, function, and regulation. CRC Press/Taylor and Francis, 2007.

15. Rybalkin SD, Yan C, Bornfeldt KE, Beavo JA: Cyclic GMP phosphodiesterases and regulation of smooth muscle function. Circ Res. 2003; 93:280.

16. Hatzimouratidis K, Hatzichristou D: Sexual dysfunctions: classifications and definitions. J Sex Med.2007; 4:241-250.

17. Gurib-Fakim A: Medicinal plants: traditions of yesterday and drugs of tomorrow. Mol Aspects Med. 2006; 27:1-93.

18. Temkitthawon $\mathrm{P}$, Changwichit K, Khorana N, Ingkaninan K: Phenanthrenes from Eulophia macrobulbon as novel phosphodiesterase-5 inhibitors. Nat Prod Commun. 2017; 12:79-82.

19. Wisutthathum S, Chootip K, Martin H, Ingkaninan K, Temkitthawon $P$, Totoson $P$, Demougeot C: Vasorelaxant and hypotensive effects of an ethanolic extract of Eulophia macrobulbon and its main compound (1-(4'-Hydroxybenzyl)-4,8dimethoxyphenanthrene-2,7-diol). Front Pharmacol. 2018; 9:484.

20. Wisutthathum S, Demougeot C, Totoson P, Adthapanyawanich K, Ingkaninan K, Temkitthawon P, Chootip K: Eulophia macrobulbon extract relaxes rat isolated pulmonary artery and protects against monocrotaline-induced pulmonary arterial hypertension. Phytomedicine. 2018; 50:157-165.

21. Changwichit K, Girard-Thernier C, Temkitthawon P, Khorana N, Ingkaninan K: Quantitative analysis of a phenanthrene from Eulophia species by TLC-image analysis method. Songklanakarin J Sci Technol. 2018; 40:1324-1328. 
22. Mirone V, Sorrentino R, di Villa Bianca R, Imbimbo C, Palmieri A, Fusco F, Tajana $\mathrm{G}$, et al.: A standardized procedure for using human corpus cavernosum strips to evaluate drug activity. J Pharmacol Toxicol Methods. 2000; 44:477-482.

23. Feelisch M, Kotsonis P, Siebe J, Clement B, Schmidt HH: The soluble guanylyl cyclase inhibitor $1 \mathrm{H}-[1,2,4]$ oxadiazolo[4,3,-a] quinoxalin-1-one is a nonselective heme protein inhibitor of nitric oxide synthase and other cytochrome P-450 enzymes involved in nitric oxide donor bioactivation. Mol Pharmacol. 1992; 56:243-253.

24. Brayden JE: Functional roles of $\mathrm{K}_{\mathrm{ATP}}$ channels in vascular smooth muscle. Clin Exp Pharmacol Physiol. 2002; 29:312-316.

25. Ko EA, Park WS, Son YK, Kim DH, Kim N, Kim HK, Choi TH, et al.: The effect of tyrosine kinase inhibitor genistein on voltage-dependent $\mathrm{K}^{+}$channels in rabbit coronary arterial smooth muscle cells. Vascul Pharmacol. 2009; 50:51-56.

26. Frew JD, Paisley K, Martin W: Selective inhibition of basal but not agoniststimulated activity of nitric oxide in rat aorta by $\mathrm{N}^{\mathrm{G}}$-monomethyl-L-arginine. $\mathrm{Br} \mathrm{J}$ Pharmacol. 1993; 110:1003-1008.

27. Moreland RB, Goldstein I, Traish A: Sildenafil, a novel inhibitor of phosphodiesterase type 5 in human corpus cavernosum smooth muscle cells. Life Sci. 1998; 62:309-318.

28. Andersson KE: Mechanisms of penile erection and basis for pharmacological treatment of erectile dysfunction. Pharmacol Rev. 2011; 63:811-859.

29. Hogan PG, Rao A: Store-operated calcium entry: mechanisms and modulation. Biochem Biophys Res Commun. 2015; 460:40-49.

30. Noguera MA, Madrero Y, Ivorra MD, D'Ocon P: Characterization of two different $\mathrm{Ca}^{2+}$ entry pathways dependent on depletion of internal $\mathrm{Ca}^{2+}$ pools in rat aorta. Naunyn Schmiedeberg Arch Pharmacol. 1998; 357:92-99.

31. Prakriya M, Lewis RS: Store-operated calcium channels. Physiol Rev. 2015; 95:1383-1436.

32. Quinn T, Molloy M, Smyth A, Baird AW: Capacitative calcium entry in guinea pig gallbladder smooth muscle in vitro. Life Sci. 2004; 74:1659-1669.

33. Ballard SA, Gingell CJ, Tang K, Turner LA, Price ME, Naylor AM: Effects of sildenafil on the relaxation of human corpus cavernosum tissue in vitro and on the activities of cyclic nucleotide phosphodiesterase isozymes. J Urology. 1998; 159: 2164-2171.

34. Noguera MA, D'Ocon MP: Different and common intracellular calcium-store mobilized by noradrenaline and caffeine in vascular smooth muscle. Naunyn Schmiedebergs Arch Pharmacol. 1992; 345:333-334.

35. Parekh AB, Putney JW Jr: Store-operated calcium channels. Physiol Rev. 2005; 85:757-810. 